of the moralist and the greatest good of the community. They who have watched the growth, in recent years, of the various efforts which are being made for the moral reformation of the metropolis, cannot fail to have been struck with the gradually increasing energy which is being infused into the different means made use of. This great and cheering sign is not, however, manifested in the metropolis alone, but it is witnessed also throughout the whole kingdom, concerning which the masterly pen of Montalembert has written :-

“.... I hail again with joy the most significant and most consoling symptom of the actual state of England-I mean the persevering ardour of the flower of the British nation in the pursuit of social and administrative reforms; of amelioration in the state of the prisons, and that of unhealthy habitations; in spreading popular, professional, agricultural, and domestic education; in the augmentation of the resources set apart for public worship; in the simplification of civil and criminal procedure; in toiling, in every way, for the moral and material wellbeing of the working classes, not by the humiliating tutelage of uncontrolled power, but by the generous combination of free agency and of every spontaneous sacrifice." - (Un Debat sur l'Inde au Parlement Anglais.)

\title{
ART. VII.-STATISTICS OF INSANITY.
}

\section{FRANCE.}

M. Legoyt, who is at the head of the French Bureau of General Statistics, published, a few months ago, a volume of statistics relative to establishments for the insane in France. The following analysis of this work, from the pen of M. Brierre de Boismont, presents a comprehensive summary of the lunacy statistics of France, and is extracted from the last number of the Annales d'Hygiene Publique. We have omitted that portion of M. Boismont's analysis which refers to expenditure and deficiencies in asylum accommodation,-

Notwithstanding the efforts made by the French administration to obtain the most complete information respecting the insane under treatment, exact data are still wanting. Idists and cretins were not distinguished in the returns until the year 1853; and there is an excess of at least 300 per annum in the figures indicative of the total number of insane, in consequence of duplicate returns. Both these sources of error will, in future, be removed.

On the 31st December, 1853, the number of lunatic establishments amounted to 111 . Of these 65 were public and 46 private. One of the public asylums belongs to the State (Charenton), 37 to the departments, 1 to the communes, and 26 are ancient religious houses or foundations, or divisions of a civil hospital (hospices ou quartiers d'hospices). Among $\mathrm{x} 2$ 
these 111 establishments, 11 are devoted specially to maies, 17 to females, and 83 receive both sexes. Twenty-five departments have still no establishments specially set apart for the insane

In 1835 , the number of insane under treatment was ascertained for the first time. Since this period, the figures have increased year by year with one exception, in 1850, during which year a decrease occurred in consequence of the mortality from cholera in 1849. The number of insane in the different asylums on the 1st of January in each year from 1835 to 1854 , inclusive, was as follows :-

$\begin{array}{cc}1835-10 \cdot 539 & 1845-17 \cdot 089 \\ 1836-11 \cdot 091 & 1846-18 \cdot 013 \\ 1837-11 \cdot 429 & 1847-19 \cdot 023 \\ 1838-11 \cdot 892 & 1848-19 \cdot 570 \\ 1839-12 \cdot 577 & 1849-20 \cdot 231 \\ 1840-13 \cdot 283 & 1850-20 \cdot 061 \\ 1841-13 \cdot 887 & 1851-21 \cdot 253 \\ 1842-15 \cdot 280 & 1852-22 \cdot 495 \\ 1843-15 \cdot 796 & 1853-23 \cdot 795 \\ 1844-16 \cdot 255 & 1854-24 \cdot 524\end{array}$

According to this table, it would appear that the population of asylums, from the 1st January, 1835, to the 1st January, 1854, has more than doubled. It has increased in nineteen years 13,985 , that is, about 1.33 per cent.

From 1842 to 1854 the number of male lunatics was 9,314 ; of female, 10,177. At the first glance we might be tempted to conclude from this difference that women had a peculiar predisposition to insanity; but as the females under treatment in asylums are more numerous than the men, the excess is dependent upon the sojourn of the latter being less than that of the former, and upon the mortality being greater among males than females.

The 23,795 insane existing in the asylums on the 1st January, 1853, were thus distributed: in the asylums of the State, the departments, and the communes, 10,839 ; in the quartiers des hospices, 7,233 ; in private asylums, 5,733. This gives for the first, 45.55 per cent.; for the second, $30 \cdot 36$; and for the last, 24.09.

On investigating the relation of the number of insane under treatment to the total population of France, at five quinquennial periods, the following results are obtained:-

1836-33,540,910 population, 11,091 insane; 1 in every 3,024 individuals.

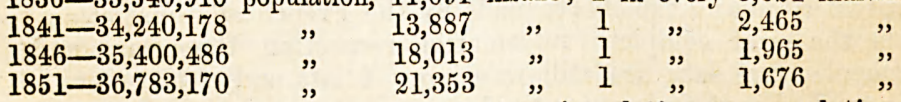

From these figures we ascertain that, in relation to population, the number of insane under treatment has augmented considerably ; for while the increase of the population from 1836 to 1851 has been 6.68 per cent., the increase of the insane has been 92.52 per cent., or nearly fourteen times as much.

But the number of insane under treatment in asylums is not an exact representation of the real number which exist; there are, indeed, many more of these unfortunates that are to be found under treatment. During the enumeration of the population in 1851, it was 
ascertained that 24,433 individuals deprived 'of reason were living in private dwelling.houses; and if this number be added to the population of the asylums in that year, we obtain a total of 44,970 insane, that is, $1 \cdot 25$ in every 1,000 inhabitants, or 1 in 796 . When the last census was taken in England, it was found that one-half of the demented individuals in that country were deprived, also, of the aid that they required, and contributed to augment the contingent of mental alienation. It is to be remarked that the departments ( 25 in number) which contain the greatest amount of insane in private dwellings, are those in which no asylums exist.

From 1842 to 1853 , with the exception of 1849 (the cholera year), there was an excess of admissions into the asylums, as compared with the united discharges and deaths, the excess amounting to an annual mean of 766 . If this proportion of admissions continue, it will be requisite every year to provide new asylums capable of accommodating the mean excess named, or to enlarge to the requisite extent the asylums already existing. The actual number of individuals received into establishments devoted to the insane, during the period named, was 94,$169 ; 52,871$ were dismissed, and 32,099 died. These figures give the annual means of 7,847 admissions, 4,406 discharges and 2,675 deaths; or 11 admissions to 10 discharges and deaths.

Of 1,000 admissions, 533 were males, and 467 females; of 1,000 discharges, before or after cure, 535 were males, and 465 females; and of 1,000 deaths, 541 were males, and 409 females: consequently, the admissions being equal, there die in lunatic asylums many more men than women; and, on the other hand, the sojourn of the latter is notably longer than that of the men. This is, as has already been said, the explanation of the numerical predominance of the female sex in the actual population of asylums.

The mean annual number of admissions, discharges, and deaths, in each of the different classes of asylums from 1844-52 inclusive, was as follows:-(1) In asylums appertaining to the State, the departments, or the communes, 5,717 (admissions, 3,138; discharges, 15,551; deaths, 1,068): (2) In hospital establishments, 6,049 (admissions, 3,066 ; discharges, 1,937 ; deaths, 1,046): (3) In maisons de santê, 3,274 (admissions, 1,752; discharges, 956; deaths, 566).

The continuous increase witnessed in the number of insane under treatment is equally remarked in the number of annual admissions: thus the figure which in 1835 was 3,947 , arose in 1853 to 9,081 . During this period of nineteen years, the total number of admissions was 128,542 . In 1852, the total number of admissions was greatest; if it be compared with 1835 , it will be found that the admissions have nearly trebled in eighteen years.

Without prejudging the question of the influence upon this increase of the number of asylums, of their enlargement, of the ameliorations which they have undergone, or of the action of civilisation upon the development of insanity, M. Legoyt presents some facts which appear to him not without interest in the solution of the problem.

He observes that, if we divide the nineteen years comprised 
between 1835 and 1853 into four periods of from three to five years each, we shall find that the mean number of annual admissions has been as follows :-

$$
\begin{aligned}
& \text { For the lst period }(1835-1838) \text {. . . . . . . } 4,378 \\
& \text { "2nd " (1839-1843) . . . . . . . . . 6,061 } \\
& \text { "3rd " } "(1844-1848) \text {. . . . . . . . } 7,510 \\
& \text { "4th " } \quad(1849-1853) \text {. . . . . . . . 8,635 }
\end{aligned}
$$

The mean increase from period to period, as deducted from these figures, is as follows:-

From the 1st to the 2 nd period 38.44 per cent., or 9.61 per cent. per annum.

" 2nd " 3rd " $" 23.91$ " 404.78 "

From this table it would appear that since 1835 the increase of admissions gradually diminishes, in such a manner that the time may be foreseen when, all things being equal, the annual number of admissions will become stationary. It may also be remarked, that if civilisation, in raising the level of general comfort, has a tendency in divers ways to excite suffering, it neutralises by degrees the deadly consequences of misery upon the public health. The increasing number of admissions can be explained by considerations every way foreign from physiological reasons: the creation of new asylums, the amelioration of the internal regime of these establishments, the extension of moral treatment, the reputation of physicians, the diminution of the prejudices respecting insanity, the moderate charges of the establishments, the rapidity of communications, and the gratuitous charge of indigent lunatics! It must also be mentioned, that lately abuses have affected the admissions, in consequence of the municipal authorities and even families imposing upon the departments, under the pretext of mental derangement, the charge of a great number of paupers. We shall not discuss these points, but contine ourselves to the remark that everywhere where the human brain is without cessation kept in action, there we are sure to see the number of insane predominate: it is thus that in France, in England, in the United States, where the physiological causes are excessively multiplied, the number of insane is considerable, while in Italy and in Spain the proportion is much less: it is also small in Turkey and in Asia. As to the predominance of moral causes above physical, we consider it incontestable; but it is necessary to know that the cause may be hid with infinite care, and that it is not in mere passing relations we shall obtain such avowals as these :- "I have failed in my duties to my spouse ;" "I have committed perjury ;" "I have seduced the sister of an intimate friend, and he has perished before my eyes," \&c., \&c. Even M. Legoyt admits that there are thousands of fools who are not treated as such, and I would add that many are carefully hidden. Lastly, the alliances between relatives, and between insane individuals, tend without ceasing to propagate the malady. M. Legoyt says that it has been demonstrated that, during the great social crisis of 1848 , there was a diminution in the number of admissions. We answer that many of these unhappy individuals fell victims to their exaltation; others fled the country; and the prisons received a large number. It has been a matter of observation, during many years, that a notable 
quantity of victims to political crises have entered into lunatic establishments. Moreover, it would be necessary to count those who, conceived under the influence of great disturbances, subsequently became insane.

On comparing the annual admissions with the population, we wrote that, during this period of 12 years, there has been in the department of the Seine 1 admission in every 516 inhabitants, while the proportion for the whole of France has been 1 in 4,144. This result is explained by the exceptional state of the city of Paris, which obliges the authorities to sequestrate every individual deprived of reason; by the just celebrity of many establishments for the insane; and by the facilities afforded to families for having their insane treated there in absolute secrecy.

The relation of the sexes ought to be examined with care. It would appear from M. Legoyt's documents, that the admissions of men have exceeded those of women in a proportion which averages more than 14 per cent. Now, it is necessary not to lose sight of the fact that there are more women than men in the total population; hence there is a certain degree of probability that man is more predisposed to insanity than woman. According to the enumeration of 1851, and the annual mean of admissions during the quinquennial period 1849-53, it would appear that, for the whole of France, there were 3,864 individuals of the male sex to every male admission, and 4,473 of the female sex for every female admission.

The admission into an asylum may be carried into effect either by the families of lunatics, or by the administration, which intervenes officially. Of the 9,081 patients cured in all the establishments in $1853,2,609$ were placed under charge by their friends, and 6,472 by the administration : thus more than two-thirds of the admissions were exacted for the public security. In the Parisian asylums, the proportion of cases sent by the administration is nearly 80 per cent.

In respect of age, from the fiftieth to the sixtieth year, females are attacked more frequently than males; in 1,000 cases of each sex, the number of instances within the period named being 134 males and 167 females. This result appears to indicate the influence of the critical time. As to the mean age of admission, it is 40 years and 5 months. One of the most remarkable facts made manifest by the returns respecting the civil condition, is the large number of unmarried people among lunatics in asylums; the percentage, of both sexes combined, upon the total number of insane under charge, being 61.80 ; while in the population at large, above the age of fifteen, the unmarried form only 36.74 per cent. This apparent predisposition to insanity among the unmarried has been attributed to the absence of those joys and cares which belong to a family, and to the terrible trials of adversity suffered alone. Without denying these reasons, M. Legoyt, bowever, thinks that it is necessary also to take into consideration the isolated state of the unmarried lunatic, which renders it necessary that he should be promptly conducted to an asylum.

In regard to professions, M. Legoyt has shown that, in proportion to their numbers, artists, in 1853, numbered eight times more insane than proprietors and landlords; Jesuits, seven times more; eccle- 
siastics and physicians, five times more; professions and men of letters, four times. For these five categories of the population combined, there were 205 individuals for one lunatic under treatment; whilst for the entire population, 1,294 inhabitants are found for one lunatic. Soldiers and sailors must be put aside altogether, because, being sent without exception, by authority, to a special establishment, there cannot be a comparison established between them and other classes of the population, of which a great number are never placed in asylums. This result confirms the opinions generally entertained, that the professions which exact continual brain-work contain a greater number of insane than others. After trades come domestics or journeymen, the manual or mechanical professions. The proportion of insane belonging to the category of domestics and of journeymen exceeds the half of the gerieral mean: it is also in this class that the greatest number of unmarried persons is found.

The degree of instruction among the insane has been the object of examination; but as there are no data respecting the amount of instruction existing among the entire population, the results have no relative value. Considering, however, the statistics in a general point of view, it is evident that that portion of the population of which the instruction is superior to that which has rudimentary instruction merely, furnishes a considerable contingent to the number of insane treated, since it forms nearly a twelfth. This proportion is nearly equal to that of the liberal professions.

Of 2,883 lunatics, in 1853 , hereditary predisposition is stated to have existed in 1,410 men and 1,470 women. Of 1,000 lunatics, the cause of insanity was said to be physical in 572, and moral in 428 . We have already remarked upon the necessity of living in intimacy with the insane in order to obtain a correct knowledge on this subject, and that the inexact information obtained in asylums, both public and private, reduces very much the value of the figures referring to heritage and other causes. There are also other objections in regard to the physical causes, because it is evident that drunkenness, bereavement, and misery have a double meaning. The man who, for example, drinks, to stupify his grief and becomes insane, at first acts under the influence of a moral cause. Accidental suppression of menses (150) and puerperal insanity (150), in a great number of cases, arise from moral impressions.

Among moral causes, the most frequent is grief arising from the loss of money : 899 cases of insanity are attributed to this cause, which is, by comparison with the total figure of moral causes, a proportion of more than 12 per cent. Afterwards comes religious exaltation $(1,894)$, love (792), violent emotions (698), pride (600), the loss of a loved one (510), disappointed ambition (495), jealousy (442), political events (308), excess of intellectual work (156), simple imprisonment (154), nostalgia (48), isolation and solitude (41), change of $\cdot$ life (32), association with and assiduous attention upon the insane (16), cellular imprisonment (4).

When the admissions are arranged according to seasons, it is seen that the months of summer and of autumn are those which are most charged. For both sexes, and for the female sex, the maximum of 
admissions takes place in July; for the male sex, in November. This difference is indicated now for the first time.

An interesting point for study is the duration of insanity at the time of reception into an asylum. Of 14,963 insane respecting whom information was furnished, in 1853 , it is noted that nearly half the number had been suffering more than two years. If this return be exact,- - and we believe, from our own experience, that it is so, - we need not be surprised at the number of insane who cumber our asylums. The English returns direct attention every year to this sad result-the result of ignorance, cupidity, and indifference.

Idiots and cretins were distinguished for the first time in the statistical returns for 1853 . In that year the number of idiots is stated to have been 2,654 , of cretins only 45 . We may remark concerning this last figure that it must be very far from being correct, for it is not in relation with the great number of existing cretins, of whom it has been estimated 3,000 exist in the department of the Basses-Alpes alone.

Insanity has been considered one of the maladies which offers the greatest number of relapses. Of the 32,876 insane which form the object of this examination, the relapses amount to 1,635 , being a proportion of 49 in every 1,000 insane. It will be acknowledged that this proportion is much less than that which occurs in many other affections, and particularly in rheumatism.

Of the 32,876 insane returns in 1853 , comprehending the 23,795 in the asylums on the 1st of January in that year, and the 9,081 received during the year, 12,972 came from towns, 14,536 from the country, and of 5,368 the residence was unknown. Now, as the population of the towns is to that of the country as 1 to 3 , it follows that the urban insane are much more numerous than the rural. This result has been attributed to the development of luxury, extreme covetousness, agitations, excesses, disorders of all kinds, industrial crises, and the miseries that they lead to. M. Legoyt, however, would attribute it to differences in administrative measures. Thus, while in towns the insane are most commonly placed in confinement as dangerous, in the country the inoffensive are left to the charge of their families; from which it follows that the towns ought to show a marked numerical superiority of insane under treatment as compared with the country. This opinion is supported by the results of the census of 1851, which show 1,856 insane in 3,632 cities and chief towns of arrondissements, and 22,577 in the communes. But it is to be observed that researches made with care by the directors of asylums demonstrate the predominance of the number of insane in towns in relation to the amount of population. There is, also, another fact which belongs to this question, that is the excess in number of suicides occurring in towns as compared with the country, and we know the intimate relation which exists between suicide and folly.

It is difficult to appreciate rightly the results afforded by the returns of cures, because the figures vary singularly according as establishments receive patients curable or incurable, as at Bethlehem or Hanwell. In France the asylums admit indiscriminately all cases, and the pro. portion of chronic cases is enormous. Some asylums make their 
returns solely upon curable cases, whilst others take the total number of admissions. To obtain an exact number of cures, it would be necessary to put aside paralytics, epileptics, demented, chronic cases, idiots, cretins, caput mortuum of which the lot is fixed in advance, and to hold count only of recent cases of mania and monomania, the sole which have a chance. In 1853 , of 4,872 cases discharged, 2,771 were cured and 2,101 not cured. Relatively to the duration of treatment in the cases cured, 36 per cent., or more than one-third, were cured within the first three months of treatment; 25 per cent., or one-fourth, after six months' treatment; 11 per cent., or about one-tenth, in from six to nine months ; 8 per cent. in from nine to twelve months. This gives, consequently, 80 per cent. of cures within the first year, and 20 per cent. only in subsequent years. The mean duration of the cures was nine months, fifteen days; and the mean age of the individuals cured, thirty-seven years, two months, for both sexes.

During the period of twelve years comprised between 1842 and 1853 , there died 32,099 individuals in lunatic asylums, or an annual average of 2,675 . Of this proportion, 17,390 were men, and 14,709 women.

If the mortality be compared in public and private asylums, we obtain the following results: ${ }^{*}-$

Departmental Asylums .1 death in $\%$

In Hospital Establishments ...1

In Maisons de Santé..............1

”

$"$

$7 \cdot 90$, or $12 \cdot 66$ per cent.
$6 \cdot 45, " 15 \cdot 60$ "
$8 \cdot 10, " 12 \cdot 35$ "

Under the denomination maisons de santé are included establishments which receive as many as 100 insane, of whom the greatest part might also be placed in the hospices : be this as it may, the mortality in the quartiers d'hospices is the most considerable. This is to be attributed to these establishments being old constructions, badly situated in the middle of towns, and not fitted for the purpose to which they are devoted. In 1853 sixteen accidental deaths and seventeen suicides occurred. This last figure is not surprising, if we reflect on the frequency of suicidal mania. We may add even, that it is providential, when we know how fixed the resolutions of the suicidal insane are. Esquirol tells us that when a lunatic wishes to kill himself, he does it in spite of precautions: this is also our conviction.

All those who have the direction of public or private asylums know the large proportion of deaths during the first month of admission. According to M. Legoyt, it reaches 108 per cent, or more than a tenth of the whole mortality; and he asks if, independently of the states of debility stated by some alienists as to the cause of mortality, the sudden change of regime, and the violent emotion occasioned by this hasty sequestration, may not have an unfavourable influence? We are astonished that emotion should be assigned as a cause, because for thirty years that we have been constantly in contact with the insane, and that we have observed them with particular care, we have never seen emotion occasion a grave accident. The immense majority of the insane have not a knowledge of their state; they are generally egoists ; many without doubt, regret their liberty, beg for it, and make attempts to

* It is not stated how these results were obtained.-ED. 
escape; but they are rarely attacked with nostalgia, and when this does occur, the dismissal takes place nearly always immediately. The mortality of the first month, then, must be attributed to other causes, and these are those which we have noted and which our confrères have noted also. A great number of cases kept a long time at home are placed in asylums only when they become noisy or refuse every attention : this happens often with general paralytics; and this state corresponds always to a period of aggravation or of fatal termination. Acute and grave cases, such as acute delirium, with obstinate refusal to take food, from fear of being poisoned by enemies, terminates also unfortunately in a few days, when the aid of art is insufficient. Many insane, treated at home, from some motive or other are sent into an asylum to die there. Lastly, it frequently happens that sick are sent to asylums who are suffering from the delirium of typhoid and ataxic fevers, encephalitis, pneumonia, \&c., and who expire a few hours after admission, or at the end of two or three days. This rapid enumeration, which does not comprehend every case, gives a satisfactory scientific explanation of the elevated figure of the mortality in the first month.

The seasons have upon the mortality of the insane the same influence that they have upon the mortality of the total population of France.

\section{IRELAND.}

The Appendix to the Report of the Commissioners of Inquiry into the State of the Lunatic Asylums, and other institutions for the custody and treatment of the Insane in Ireland, contains a series of statistical tables relative to the district asylums, from which several interesting particulars may be obtained respecting the recoveries, mortality, and character of the cases received into those institutions. In our last number we gave an account of the nature and tendency of the Commissioners' Report; we now propose to lay before our readers a few of the principal results which may be gathered from the Appendix.

In our previous notice of the Report, we gave a summary of the general statistics contained in it, but we may quote here the following statement of the Commissioners:- "The Census Commissioners (1851) and the Inspectors of Lunatics in their last Report have given returns of the total number of insane in Ireland in 1851 and 1857 respectively. The returns of the inspectors are not given for the same date in the several institutions, and they contain, moreover, the number of persons simply 'epileptics' at large and in the workhouses; and as these are exclusive of the 'lunatics' and 'idiots' in those returns, they may be omitted from the total of the insane. The Census Returns give the number of insane in Ireland on the 31st March, 1851, at 9,980, of whom 4,635 were at large. The Inspectors of Lunatics, in their last Report (if we exclude epileptics at large and in workhouses, for those in asylums must be supposed to be insane), fix the number at 11,452 , of whom 5,441 are at large. A comparison of these returns, made at an interval of between five and six years, and obtained through the same sources of information, shows a considerable increase in the amount of insanity in Ireland."-Report, p. 2. 
During the five years $1852-56,6,197$ cases (3,249 males and 2,948 females) were admitted into the district asylums, and the daily average of patients during the period was 3,467 . The total discharges amounted to 3,715 (1,936 males, 1,779 females), the recoveries being 2,435 (1,237 males, 1,298 females), and the non-recoveries 1,280 (699 males, 581 females). The total mortality was 1,363 (722 males and 641 females). If the proportion of recoveries and deaths be calculated upon the admissions, it is found that the average ratio of the former during the five years was $39 \cdot 2$ per cent., of the latter 10.5 per cent.; but if the more correct calculation suggested by Dr. Farr be made, the proportions being calculated upon the mean of the admissions, discharges and deaths-this mean giving the nearest approximation to the number of cases treated-the following results, per cent., are obtained:-Recoveries, males $21 \cdot 9$, females $21 \cdot 2$, total $43 \cdot 1$ : Deaths, males $12 \cdot 8$, females $10 \cdot 3$, total $22 \cdot 7$.

The distribution of the deaths in the different months was as follows :

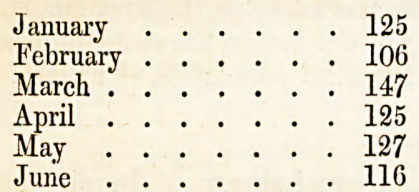

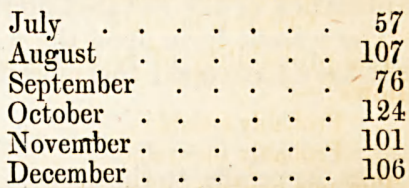

From these figures it would appear that the maximum mortality was in spring, the minimum in summer.

The accompanying figures show the proportion per cent. of recoveries within different periods of time :-

Less than three months.

$\begin{array}{ccr}\text { Males. } & \text { Females. } & \text { Total. } \\ 15 \cdot 1 & 13 \cdot 4 & 28 \cdot 2 \\ 11 \cdot 9 & 12 \cdot 5 & 22 \cdot 7 \\ 11 \cdot 5 & 11 \cdot 6 & 23 \cdot 5 \\ 6 \cdot 2 & 5 \cdot 3 & 11 \cdot 6 \\ 2 \cdot 4 & 2 \cdot 4 & 5 \cdot 3 \\ 1 \cdot 3 & 0 \cdot 9 & 27 \cdot 9 \\ & & 12 \cdot 3 \\ & & 9 \cdot 0 \\ & & 4 \cdot 9 \\ & & 3 \cdot 2 \\ & & 2 \cdot 4 \\ & & 4 \cdot 5 \\ & & 0 \cdot 8\end{array}$

More than three months and less than six months

More than six months and less than one year . .

More than one year and less than two years,. .

More than two years and less than three . . .

More than three years and less than four . . . .
More than four years and less than five . . .

More than five years and less than six . . .

More than six years and less than seven ......

More than seven years and less than eight. .

More than eight years and less than nine ...

More than nine years and less than ten . . .

More than ten years

\section{7} 76 24 01

Thus, more than one-fourth of the recoveries took place within three months after admission into an asylum; one-half within the six months; and three-fourths within twelve months.

Of the admissions during the five years 22.0 per cent. $(11.9$ males, 10.3 females) had been in an asylum once before; $2 \cdot 5$ per cent. ( $1 \cdot 1$ males, and 1.4 females) had been twice before; and 1.1 per cent, ( 0.9 males, 0.8 females) had been thrice.

The form of mental disease and special tendencies, as well as the probable curability and incurability of the patients in the different asylums on the 1st January, 1857, is shown in the subsequent summary. 
The figures show the per-centage upon the total number of patients, namely 3,284 ( 1,949 males, and 1,875 females).

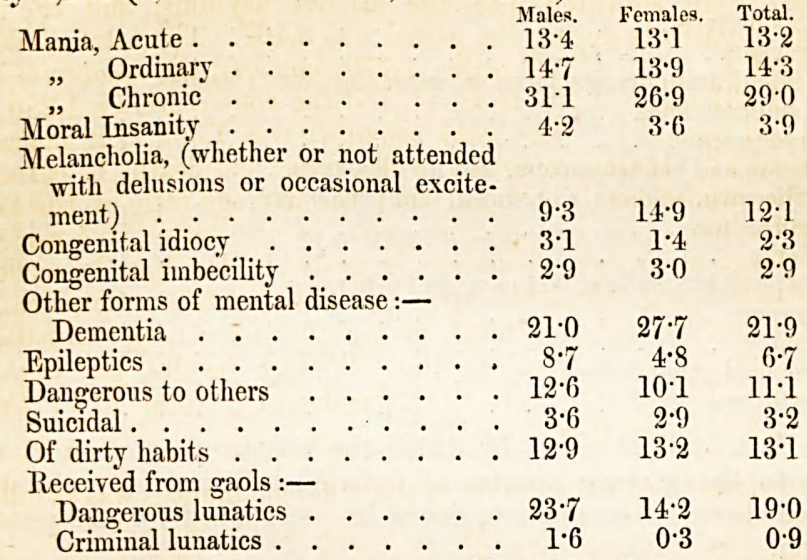

The probability of recovery among the whole of these cases was as follows :-

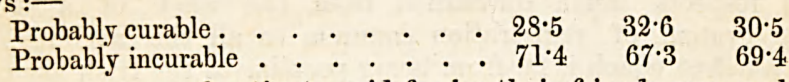

The per-centage of patients paid for by their friends was, males $2 \cdot 0$, females $1 \cdot 0$, total $1 \cdot 5$.

The assigned causes of the mental disorder in the cases admitted into the district asylums during the five years 1852-56 may be divided into two classes, the physical and the moral. In the first class there may be enumerated, of those cases in which a cause is distinctly specified, 722 males and 707 females; in the second class may be summed up 262 males, and 461 females. The principal physical causes mentioned and the number of cases in which they are supposed to have been effective, are as follows :-

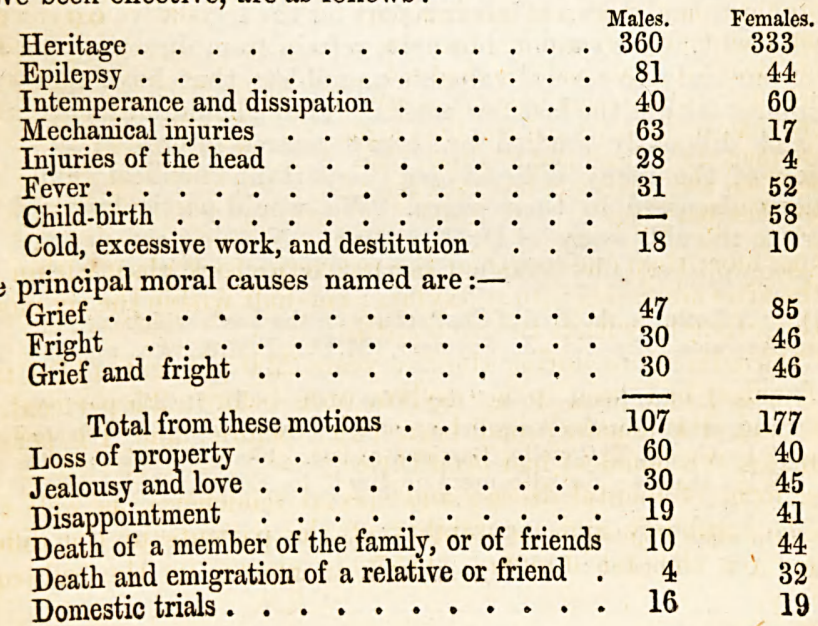


The occupation of the lunatic prior to his insanity is mentioned in 3,794 instances, of which the accompanying list gives a brief summary :

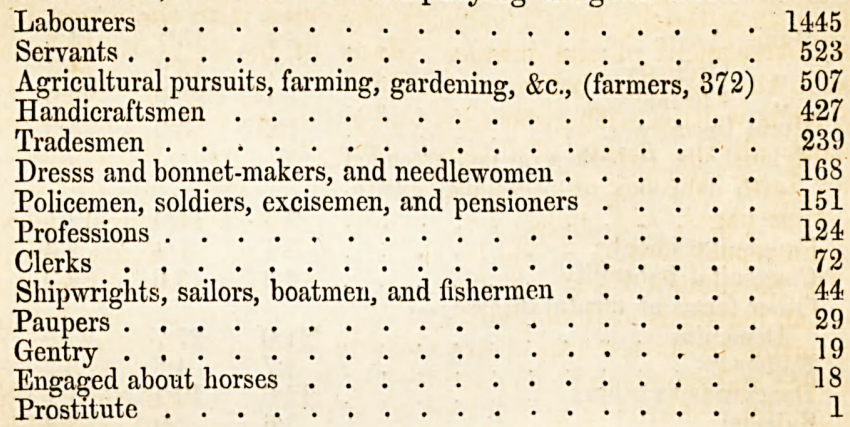

The data are not given by which the relative proportion of these figures to the average number of individuals living in each of the specified classes of occupation, could be ascertained for the period in question.

The value of the statistics furnished by the district asylums is in several respects much diminshed from the want of a comprehensive system of registration common to all the asylums. But this is a defect which is far from being peculiar to the Irish asylums.

\section{PROPOSED AMENDMENT OF THE LAW OF LUNACY.*}

Ir was our intention to have discussed at a considerable length this important subject, but as the matter in all its details is at this moment under the consideration of a committee of the House of Commons, and witnesses are in the course of examination, we have thought it would be in better taste, and more consistent with the public good, to defer the publication of our remarks until the committee have completed their labours, and drawn up their report for the legislative consideration of Parliament. We cannot, however, refrain from directing the attention of our body to several valuable pamphlets that have appeared on this subject within the last few weeks. They should all be attentively read and diligently studied by every person interested in a right solution of the many difficult and important medical and social questions discussed in their pages. We would particularly refer our readers to the able essay of Dr. Seymour. Nothing can proceed from this accomplished physician's pen that is not entitled to the most

* (1). "A Letter to the Earl of Shaftesbury on the Laws which regulate Private Lunatic Asylums," by Ed. J. Seymour, M.D., F.R.S., \&c. pp. 59, Longman: 1859 .

(2). "Plea for the Insane Poor," by John Millar. H. Renshaw : 1859.

(3). "Suggestions for the Amendment of the Laws relating to Private Lunatic Asylums," by G. Ed. T. Conolly, Barrister-at-law. Shaw and Sons : 1859.

(4). "What shall we do with our Lunatics?" by Edward Eccles, F.R.C.S. J. Churchill: 1859.

(5). "On some Points in the Legal Provisions for the Poor," by J. T. Arlidge, M,B, and A.B. London : 1859 . 